\title{
Peningkatan Kompetensi guru Akuntansi dalam Pengajaran Komputer Akuntansi
}

\author{
Elfitri Santi $^{1}$, Rasyidah Mustika ${ }^{2}$, dan Endrawati ${ }^{3}$ \\ Jurusan Akuntansi, Politeknik Negeri Padang \\ ${ }^{1}$ Email: elfitrisanti@ymail.com \\ 2 Email: titik.mustika@gmail.com \\ ${ }^{3}$ Email: endrawati@pnp.ac.id
}

\begin{abstract}
The development of technology has been very rapid and the curriculum has lagged far behind. This requires a curriculum change. SMK has made this change but in its development it is no longer relevant. Teachers as the spearhead of successful learning in schools must have competencies that are relevant to the development needs of the industry. This activity aims to improve the ability of Accounting MGMP teachers in West Sumatra province in learning computer accounting (Accurate). The approach taken in this research is a case study. The training process starts from application installation, creation of new company files, input transactions, and preparation of financial reports. The activity went well, but some teachers still needed further training and a whatsapp group was formed for further discussion. The obstacles faced were participants who were not familiar with computers.
\end{abstract}

\begin{abstract}
ABSTRAK
Perkembangan teknologi sudah sangat pesat dan kurikulum sudah tertinggal jauh dibelakang. Hal ini menuntut dilakukannya perubahan kurikulum. SMK telah melakukan perubahan ini namun dalam berkembangannya juga sudah tidak relevan lagi. Guru sebagai ujung tombak keberhasilan pembelajaran di sekolah harus memiliki kompetensi yang relevan dengan perkembangan kebutuhan industry Kegiatan ini bertujuan untuk meningkatkan kemampuan guru MGMP Akuntansi di propinsi Sumatera Barat dalam pembelajaran komputer akuntansi (Accurate). Pendekattan yang dilakukan pada penelitian ini adalah studi kasus. Proses pelatihan dimulai dari instalasi aplikasi, pembuatan file perusahaan baru, input transaksi, dan pembuatan laporan keuangan. Kegiatan berjalan lancar, namun beberapa guru masih membutuhkan pelatihan lebih lanjut dan dibentuk group whatsapp untuk diskusi lebih lanjut. Kendala yang dihadapi adalah peserta yang tidak familiar dengan komputer.
\end{abstract}

Kata kunci: Komputer Akuntansi, Kompetensi, Pelatihan, Pembimbingan, skills keterampilan, Pendidikan akuntansi

\section{Pendahuluan}

Perkembangan teknologi sudah sangat pesat dan kurikulum sudah tertinggal jauh dibelakang. Sejak pertengahan 1980-an, badan akuntansi profesional, pengusaha lulusan akuntansi dan akademisi sama-sama menyesalkan kegagalan universitas untuk membekali lulusan akuntansi dengan kompetensi yang dibutuhkan untuk lingkungan bisnis modern (Bui \& Porter, 2010). Hal ini terjadi karena perubahan dramatis dalam lingkungan bisnis di abad kedua puluh satu, tuntutan akan keterampilan dan sifat pengajaran, pembelajaran, dan penilaian dalam setiap disiplin ilmu berkembang (Gunarathne et al., 2019). 
Pada umumnya, usaha kecil menengah (UKM) telah menggunakan software computer dalam bisnis mereka. Software yang digunakan antara lain pengolah kata (word), paket akuntansi, spreadsheet, database, sistem informasi manajemen terintegrasi, dan paket statistik (Azih, 2013). Akuntansi elektronik memiliki manfaat dan kegunaan bagi perusahaan sekaligus dalam pendidikan akuntansi. Untuk itu Paket akuntansi elektronik harus dimasukkan dalam kurikulum semua program yang menawarkan program pendidikan akuntansi (Bridge \& Peel, 1999).

Kurikulum secara sistimatis harus direview dan secara berkala diupdate agar mencerminkan trend sekarang dan merefleksikan permintaan tenaga kerja. (Abayadeera et al., 2016). Kurikulum SMK sudah menyesuaikan kurikulum dengan kebutuhan industri. Hal ini ditandai dengan telah diberikannya mata pelajaran Komputer Akuntansi. Namun aplikasi yang diajarkan ini mempunyai beberapa kelemahan. Kelemahan tersebut belum mengakomodir aturan dan kebutuhan perusahaan-perusahaan di Indonesia karena dibuat oleh Lembaga luar negeri. Disamping itu, aplikasi ini diperuntukan kepada perusahaan yang berbentuk perseroan, sehingga perusahaan perseorangan maupun firma/CV kesulitan menggunakan aplikasi ini. Kelemahan lain adalah software ini belum dilengkapi fasilitas penghitungan penyusutan asset tetap. SMK di Sumatera Barat telah memutuskan untuk memberikan pengajaran aplikasi akuntansi yang baru yaitu Accurate.

Pada tahun 1999, CPSSoft merilis aplikasi akuntansinya, yaitu Accurate. Aplikasi komputer akuntansi, Accurate, merupakan aplikasi yang disusun menggunakan aturan PSAK (standar akuntansi yang digunakan di Indonesia), memiliki kualitas yang andal dan terpercaya, dimana $80 \%$ pengguna telah merekomendasikan aplikasi ini kepada rekan bisnisnya. Accurate juga memilliki kemudahan dalam pemakaian sehingga telah banyak digunakan oleh perusahaan di Indonesia. Fitur lain yang dimiliki accurate adalah fasilitas penghitungan penyusutan aktiva tetap dan faktur pajak yang sesuai dengan aturan yang berlaku (CPSoft, 2015).

Guru sebagai ujung tombak keberhasilan pembelajaran di sekolah harus memiliki kompetensi yang relevan dengan perkembangan kebutuhan industry. Selain guru memiliki kompetensi mengajar dan mendidik, literasi media, competence in globalization, competence in future strategies, dan konseling, juga perlu memiliki sikap ramah teknologi, kolaborasi, menjadi kreatif dan mengambil resiko, memiliki selera humor yang baik, serta mengajar secara holistic (Lase, 2019). Teknologi bertransformasi demikian pula dunia Pendidikan. Transformasi ini mengakibatkan banyak perubahan dan pergeseran peran, termasuk dalam dunia Pendidikan, khususnya bidang keguruan. Namun peran guru tidak bisa digantikan oleh teknologi dalam memberikan Pendidikan karakter, moral, dan keteladanan (Risdianto, 2019)

Sumberdaya yang ada belum memadai untuk melakukan transfer ilmu kepada siswanya, hal ini disebabkan kurangnya pelatihan yang diberikan kepada guru. Guru perlu dilatih tidak hanya dalam teknologi pengajaran online, tetapi juga dalam merancang kursus pendidikan online. Pendidikan jarak jauh memiliki janji luar biasa dalam memungkinkan perguruan tinggi dan universitas menawarkan siswa kursus berkualitas dalam format yang fleksibel, dan popularitasnya yang semakin meningkat menunjukkan bahwa ia akan terus ada. (Salimi; 2007). Peningkatan kompetensi guru dapat dilakukan dengan berbagai cara antara lain melalui kualifikasi akademik guru, pendidikan dan pelatihan, uji sertifikasi, memberi kesempatan perbaikan pembelajaran (Sukanti, 2008). 
Proses pelatihan bertujuan untuk pelatihan akuntansi dan individu yang memiliki kebebasan dan karakter masing-masing dari praktik pedagogis guru akuntansi (Laffin \& Gomes; 2014). Hal ini perlu diatasi dengan mendorong dan memberikan metode pelatihan yang sesuai sehingga proses transfer ilmu dari pelatih kepada guru akuntansi berjalan dengan efektif. Namun dalam pelatihan ini perlu diperhatikan latar belakang dan budaya dari perserta pelatihan. Pelatihan dapat berjalan dengan efektif haruslah memperhatikan isi dan metode, pemilihan pelatih, motivasi dan gaya belajar (Yang at all; 2009).

Guru-guru Akuntansi yang tergabung dalam MGMP Akuntansi dan Keuangan Lembaga berasal dari berbagai daerah di propinsi Sumatera Barat. Beberapa peserta adalah guru yang belum pernah mengajar computer akuntansi, dan sebagian besar masih belum familiar dengan komputer. Pemakaian computer masih sebatas penggunaan perangkat lunak pengolah kata. Sedikit yang sudah 'akrab' dengan komputer dan yang sudah berpengalaman dalam pengajaran komputer akuntansi. Guru yang sudah mengajar komputer akuntansi ini mengajar software yang berbeda dengan software yang akan dilatihkan. Jadi, software yang akan dialihteknologikan kepada guru-guru tersebut adalah software yang baru dan memiliki tampilan serta fitur yang berbeda dengan software komputer akuntansi yang selama ini mereka ajarkan.

Berdasarkan analisis situasi dan permasalahan yang dihadapi oleh MGMP Akuntansi dan Keuangan Lembaga Sumatera Barat, maka dirancanglah program pelatihan Accurate yang sesuai dengan kebutuhan kurikulum SMK. Pelatihan dirancang sedemikian rupa sesuai dengan latar belakang peserta sehingga dapat berjalan dengan efektif.

\section{Metode}

Metode tranfer ilmu yang digunakan adalah pelatihan dan pembimbingan pengajaran aplikasi computer akuntansi Accurate. Prinsip pemberdayaan dengan memperhatikan latar belakang peserta pelatihan. Bahan yang digunakan adalah modul pelatihan, software Accurate versi edukasi, dan komputer serta peralatan pendukung untuk pengajaran komputer seperti infocus dan jaringan listrik.

Rangkaian kegiatan terdiri dari beberapa tahap, mulai dari pendataan peserta, persiapan, pembuatan modul, dan pelatihan serta evaluasi kegiatan. Kegiatan ini melibatkan taskforce pengabdian kepada masyarakat, pelatih, mahasiswa dan MGMP Akuntansi dan Keuangan Lembaga serta Kepala Sekolah SMKN 2 Padang.

Pada gambar 1, dapat dilihat mekanisme kegiatan dan pendampingan accurate pada MGMP Akuntansi dan Keuangan Lembaga di Sumatera Barat terdiri dari beberapa tahap. Tahap 1, survey awal dilakukan untuk memastikan kondisi dan kebutuhan mitra. Kegiatan ini melibatkan taskforce kegiatan dan pengurus MGMP. Informasi awal diperoleh informasi bahwa kurikulum akuntansi telah mengalami perubahan dan perlu menambah materi aplikasi computer akuntansi, khususnya accurate. Namun sedikit dari guru-guru akuntansi yang memahami dan trampil dalam pengajaran software ini. Diperoleh kesepakatan dengan pengurus untuk mengadakan kegiatan pelatihan accurate dalam rangka peningkatan kompetensi guru akuntansi dan mengakomodir perubahan kurikulum. Jumlah peserta yang disepakati adalah 20 orang dan lokasi di SMKN 2 Padang serta computer yang akan digunakan adalah komputer/laptop masing-masing peserta. 


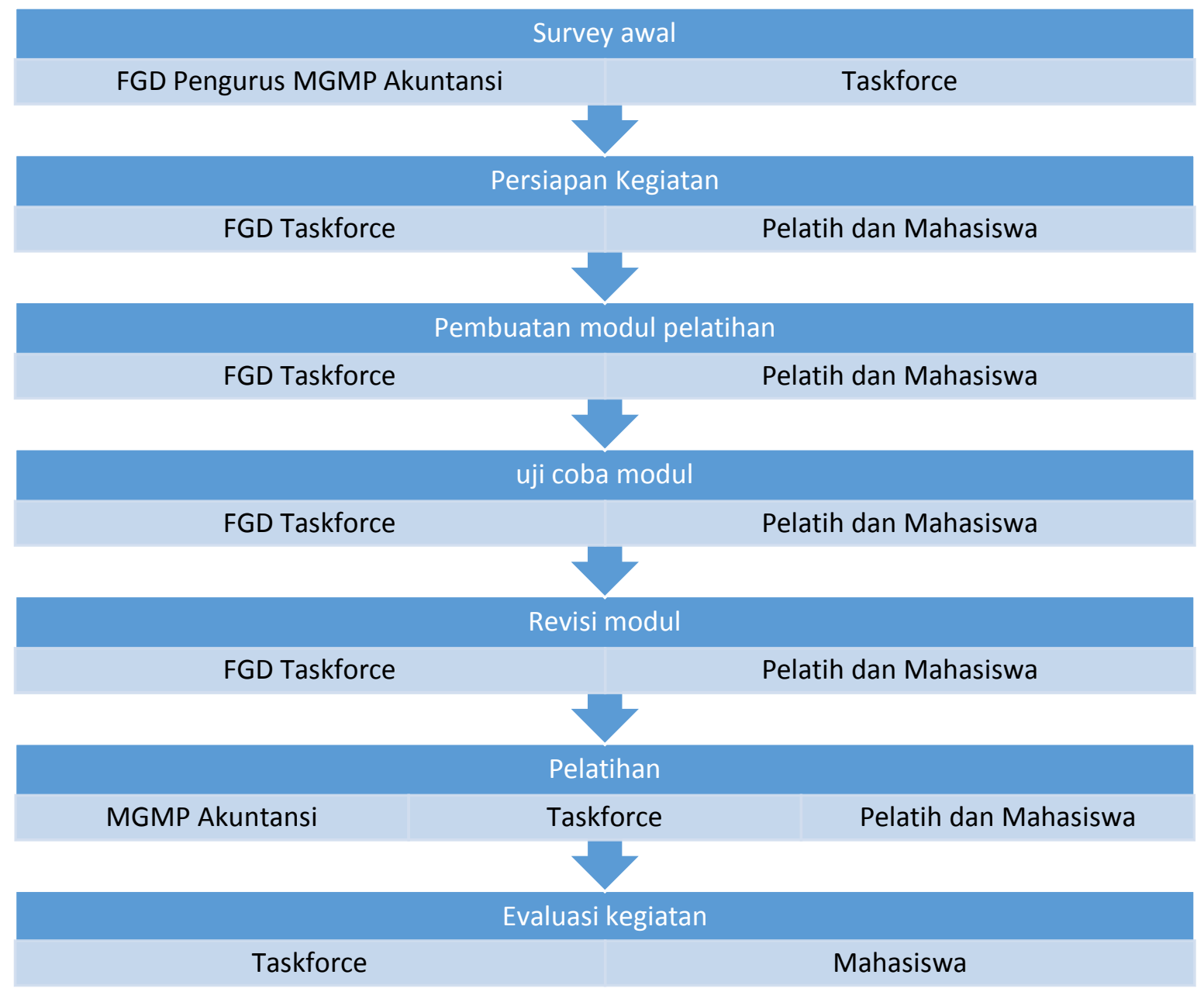

Gambar 1. Mekanisme Pelatihan dan Pendampingan Accurate pada MGMP Akuntansi dan Keuangan Lembaga di Sumatera Barat

Pada tahap kedua, taskforce melaksanakan rapat persiapan, yang melibatkan pelatiha dan mahasiswa. Pelatih dan mahasiswa selanjutnya akan terlibat dalam kegiatan ini. Mahasiswa dibutuhkan sebagai fasilitator pelatihan yang akan mendampingi langsung peserta pada saat pelatihan. Tahap selanjutnya adalah pembuatan modul, mulai dari perancangan, uji coba, dan revisi modul. Modul merupakan salah satu bahan ajar kategori bahan cetak (printed) berdasarkan pengelompokan teknologi yang digunakan (Oktavia et al., 2018)

Kemudian kegiatan dilanjutkan dengan pelaksanaan pelatihan. Pelatihan diawali dengan instalasi software accurate di laptop masing-masing peserta. Hal ini membutuhkan waktu 1 hari karena banyak peserta yang belum memahami proses instalasi ini. Kendala lain yang dihadapi adalah laptop yang perlu diset agar bisa menerima instalasi software. Setelah software selesai diinstal, kemudian dilanjutkan dengan awareness Accurate. Hal ini dilakukan karena pada umumnya peserta belum mengenal accurate.

Kegiatan terakhir adalah evaluasi kegiatan untuk menilai kinerja dan ketercapaian tujuan pelatihan. Hal ini dilakukan agar diperoleh masukan guna perbaikan dimasa yang akan datang. 


\section{Hasil Dan Pembahasan}

Kegiatan ini bertujuan untuk meningkatkan kompetensi guru-guru Akuntansi di SMK yang tergabung dalam MGMP Akuntansi dan Keuangan Lembaga di Sumatera Barat. Guru-guru diharapkan dapat memberikan pengajaran accurate di sekolah masingmasing.

Pelaksanaan kegiatan dan pendampingan accurate pada MGMP Akuntansi dan Keuangan Lembaga di Sumatera Barat berjalan lancer. Tahap 1, survey awal dilakukan untuk memastikan kondisi dan kebutuhan mitra. Kegiatan ini melibatkan taskforce kegiatan dan pengurus MGMP. Informasi awal diperoleh informasi bahwa kurikulum akuntansi telah mengalami perubahan dan perlu menambah materi aplikasi computer akuntansi, khususnya accurate. Namun sedikit dari guru-guru akuntansi yang memahami dan trampil dalam pengajaran software ini. Diperoleh kesepakatan dengan pengurus untuk mengadakan kegiatan pelatihan accurate dalam rangka peningkatan kompetensi guru akuntansi dan mengakomodir perubahan kurikulum. Jumlah peserta yang disepakati adalah 20 orang dan lokasi di SMKN 2 Padang serta computer yang akan digunakan adalah computer/laptop masing-masing peserta. Namun kemudian guru-guru akuntansi yang lain ikut sebanyak 30 orang, sehingga total peserta menjadi 30 orang.

Pada tahap kedua, taskforce melaksanakan rapat persiapan, yang melibatkan pelatiha dan mahasiswa. Pelatih dan mahasiswa selanjutnya akan terlibat dalam kegiatan ini. Mahasiswa dibutuhkan sebagai fasilitator pelatihan yang akan mendampingi langsung peserta pada saat pelatihan. Tahap selanjutnya adalah pembuatan modul, mulai dari perancangan, uji coba, dan revisi modul.

Kemudian dilanjutkan dengan pelaksanaan pelatihan. Pelatihan diawali dengan instalasi software accurate di laptop masing-masing peserta. Hal ini membutuhkan waktu 1 hari karena banyak peserta yang belum memahami proses instalasi ini. Kendala lain yang dihadapi adalah laptop yang perlu diset agar bisa menerima instalasi software. Setelah software selesai diinstal, kemudian dilanjutkan dengan awareness Accurate. Hal ini dilakukan karena pada umumnya peserta belum mengenal accurate.
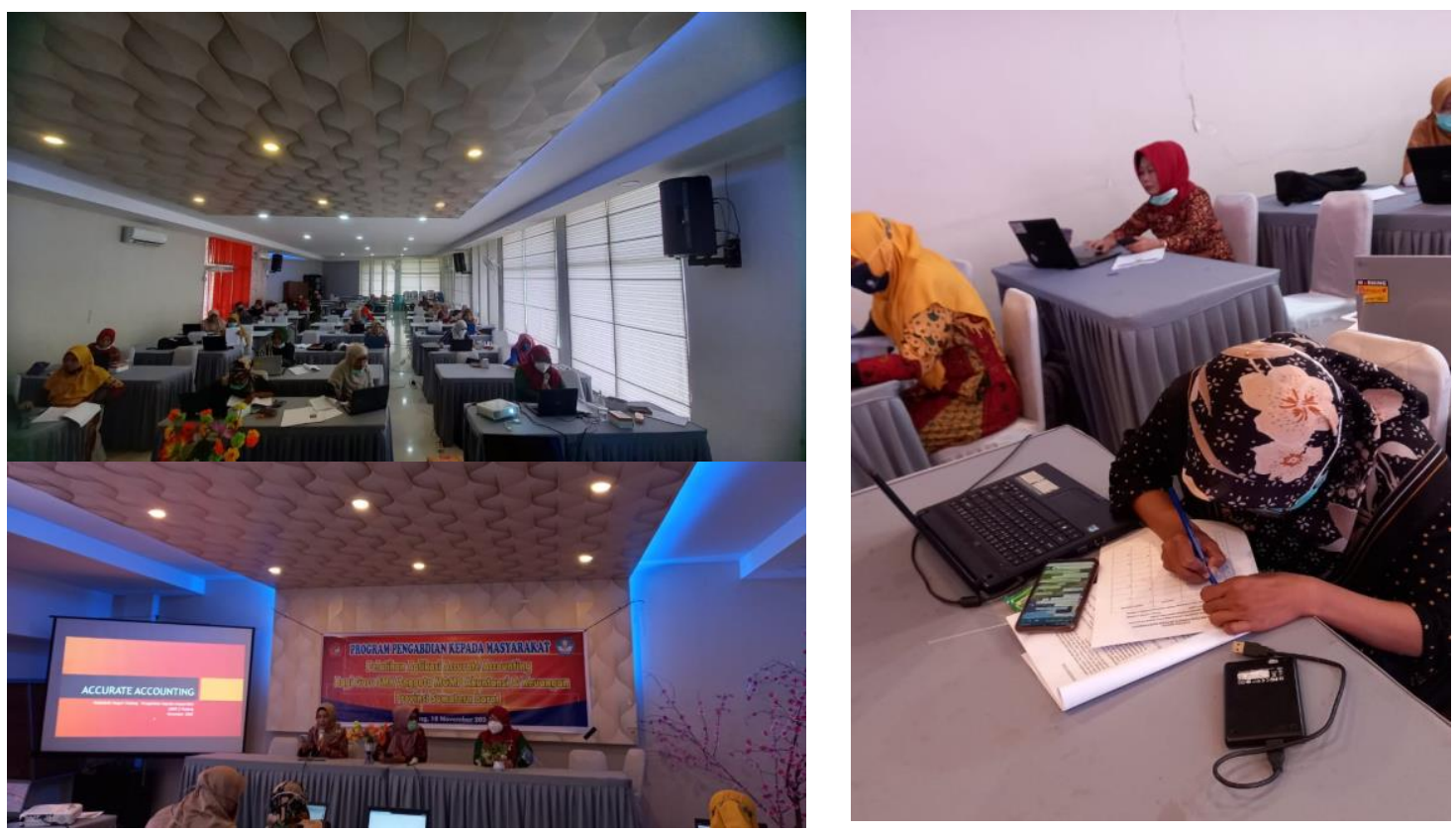

Gambar 2. Pelatihan Accurate di SMK 2 Padang 
Pelatihan diberikan oleh 2 orang pelatih dibantu 2 orang fasilitator dari mahasiswa Akuntansi PNP. Pelatihan berjalan lancer dan cukup berhasil. Hal ini dapat dilihat dari antusias peserta dalam mengikuti pelatihan. Kegiatan pelatihan berikutnya adalah mulai menggunakan accurate menggunakan kasus perusahaan dagang. Pada gambar berikut dapat dilihat foto pelatihan. Pelatihan meliputi;

- Awareness Accurate

- Setup Awal Database

- Instalasi Accurate

- Membuat database baru

- Quick setup

- Daftar mata uang

- Informasi perusahaan

- Daftar akun

- Persiapan referensi

- Daftar lain

- Pembuatan neraca percobaan dan proses penyelesaian neraca

- Pencatatan transaksi

- Modul pembelian

- Modul penjualan

- Warehouse dan inventory

- Buku Besar

- Cash \& Bank

- Aktiva Tetap

- Menu file

- Membuka database

- Profil pengguna

- Simpan dengan alias

- Cadangan file

- Pakai data cadangan

- Troubleshooting accurate

- Report

- Pembuatan laporan keuangan

- Proses tutup buku

Kegiatan terakhir adalah evaluasi kegiatan untuk menilai kinerja dan ketercapaian tujuan pelatihan. Hal ini dilakukan agar diperoleh masukan guna perbaikan dimasa yang akan datang. Hasil evaluasi pelatihan menunjukan keberhasilan pelatihan yang dapat dilihat dari semua peserta mengikuti pelatihan sampai selesai dan antusias melakukan instruksi pelatih. Namun ada beberapa kendala yang dialami, yaitu keterbatasan waktu pelatihan. Hal ini menyebabkan tidak semua aspek tentang accurate bisa disampaikan. Accurate memiliki cukup banyak tahapan, mulai dari dasar sampai tingkat lanjut. Pada kegiatan ini masih bersifat dasar. Pada kegiatan berikutnya, dimungkinkan untuk memberikan materi yang lebih dalam lagi, seperti penggunaan accurate untuk perusahaan dagang, manajemen proyek, pengelolaan persediaan dan troubleshooting accurate.

Kegiatan pelatihan telah dipublikasikan di beberapa media online dan offline. Seperti terlihat pada gambar 3. Publikasi offline di koran Haluan terbit tanggal 12 november 2020 dan publikasi online di website berita hantaran.co 


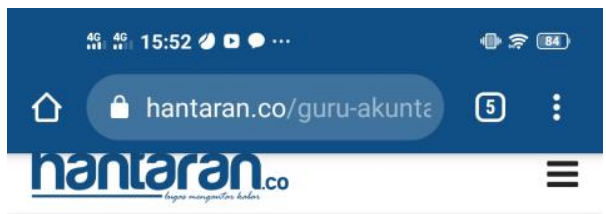

\section{Guru Akuntansi se-Sumbar Dapat Pelatihan Program Accurate Accounting}
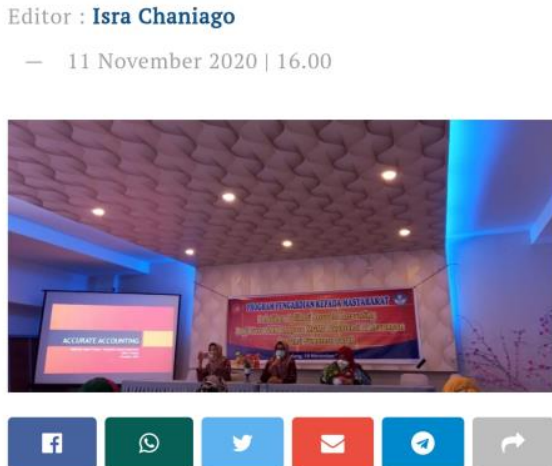

PADANG, hantaran.co - Dosen Politeknik Negeri Padang (PNP) memberikan pelatihan program Accurate Accounting untuk penyusunan laporan keuangan ke Musyawarah Guru Mata Pelajaran (MGMP) Akutansi se-Sumatera - $\quad$.

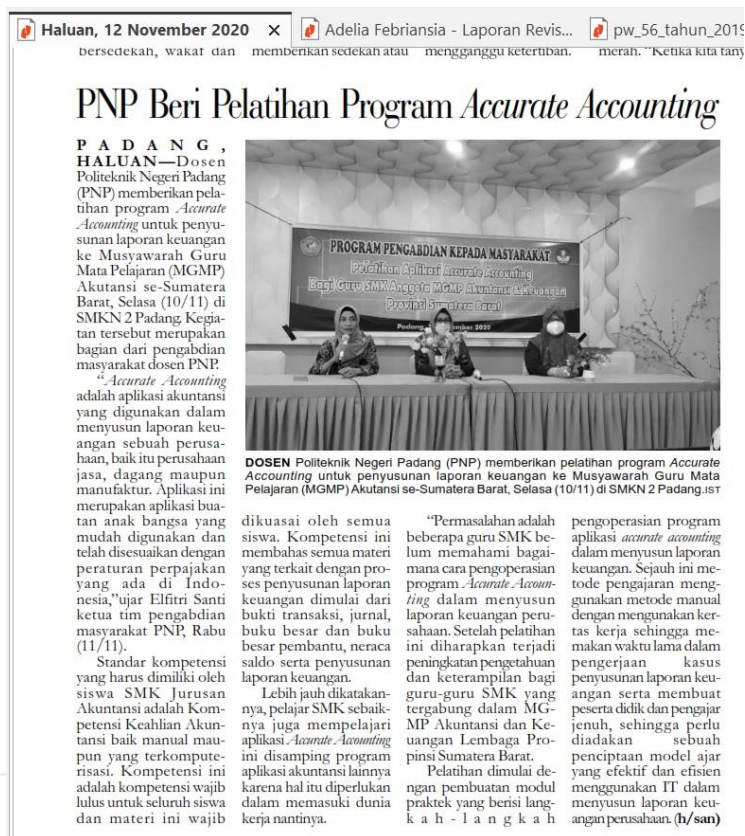

Gambar 3. Publikasi kegiatan pelatihan

\section{Kesimpulan dan Saran}

Kegiatan berjalan lancar, namun beberapa guru masih membutuhkan pelatihan lebih lanjut dan dibentuk group whatsapp untuk diskusi lebih lanjut. Kendala yang dihadapi adalah peserta yang tidak familiar dengan komputer. Agar menghasilkan hasil yang maksimal, kegiatan tidak bisa dilaksanakan dalam waktu yang singkat. Dibutuhkan beberapa tahap kegiatan yang lebih lama agar peserta benar-benar memahami accurate ini.

\section{Ucapan Terima Kasih}

Terimakasih penulis ucapkan kepada semua pihak yang telah membantu dan mendukung penelitian ini yaitu Politeknik Negeri Padang selaku institusi tempat penulis bekerja, P3M Politeknik Negeri Padang, Kepala Sekolah SMKN 2 Padang, MGMP Akuntansi Sumatera Barat dan tim pelaksana pengabdian, sehingga berjalan dengan baik dan memberikan hasil yang bermanfaat bagi pengguna

\section{Referensi}

Abayadeera, N., Watty, K., \& Zhou, H. (2016). Generic Skills in Accounting Education in a Developing Country: Exploratory Evidence from Sri Lanka. Asian Review of Accounting.

Azih, N. (2013). Electronic Accounting: An Imperative Tool for Quality Assurance in 
Accounting Education Programme in The Digital Era. Nigerian Journal of Business Education (NIGJBED), 1(2), 90-98.

Bridge, J., \& Peel, M. J. (1999). A Study of Computer USage and Strategic Palnning in the SME Sector. International Small Business Journal, 17(4), 82-87. https://doi.org/https://doi.org/10.1177/0266242699174005

Bui, B., \& Porter, B. (2010). Expectation-Performance Gap In Accounting Education: An Exploratory Study. Accounting Education, 19(12), 23-50.

CPSoft. (2015). Manual Book Accurate versi 5.

Gunarathne, N., Senaratne, S., \& Senanayake, S. (2019). Outcome-based education in accounting. Journal of Economic and Administrative Sciences, 36(1), 16-37. https://doi.org/10.1108/jeas-08-2018-0093

Lase, D. (2019). Jurnal sundermann.

Oktavia, B., Zainul, R., Guspatni, \& Putra, A. (2018). Pengenalan Dan Pengembangan EModul Bagi Guru- Guru Anggota MGMP Kimia dan Biologi Kota Padang Panjang. INA-Rxiv. https://doi.org/10.31227/osf.io/yhau2

Risdianto, E. (2019). Analisis Pendidikan Indonesia di Era Revolusi Industri 4.0.1-16.

Sukanti. (2008). Meningkatkan Kompetensi Guru Melalui PElaksanaan Penelitian Tindakan Kelas. Jurnal Pendidikan Akuntansi Indonesia, VI(1), 1-11. 